\title{
引水等综合整治后杭州西湖氮、磷营养盐时空变化(1985-2013 年)"
}

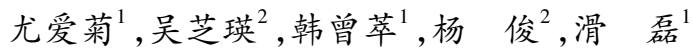 \\ (1: 浙江省水利河口研究院,杭州 310020$)$ \\ (2:杭州市西湖水域管理处,杭州 310002)
}

摘 要: 经引水等综合整治后, 西湖外湖、西里湖总磷 (TP) 浓度累计下降 $58 \%$ 和 $78 \%$, 总氮 (TN) 浓度累计下降 $16.7 \%$ 和 $7.7 \%$, 透明度提高 $100 \% \sim 200 \%$, 富营养状态得到极大缓解. 比较 1986 年治理前, 西湖各湖区因来水、引水和排水格局差 异较大, TP 浓度的年内变化特点及驱动因素也存在较大差异: 杨公堤以西的上游湖区因优质水源补充 $\mathrm{TP}$ 浓度总体较低, 同时受流域降雨径流面源输人影响, 呈现时段性升高; 杨公堤和苏堤之间的中游湖区优质水源补充量最大, 湖区水体更 新最快, TP 浓度最低且变化相对最为稳定; 苏堤以东的外湖区水体更新相对最慢, 在夏、秋高温季节因底泥污染释放, TP 浓度出现峰值. 因外来引水量大且未经脱氮处理,西湖各湖区 $\mathrm{TN}$ 年内变化基本与钱塘江取水口 $\mathrm{TN}$ 浓度变化一致,同时 因流域降雨径流面源输人而出现时段性波动. 基于 TP 质量平衡模型分析, 各湖区水质空间差异主要受水体年交换次数 影响,其次受单位水体的年污染负荷影响.

关键词: 西湖;总磷; 总氮; 时空分布; 影响因子

\section{Spatial and temporal distributions and variations of nutrients in the West Lake, Hang- zhou, after the implementation of integrated water management program (1985-2013)}

\author{
YOU Aiju ${ }^{1}$, WU Zhiying ${ }^{2}$, HAN Zengcui ${ }^{1}$, YANG Jun $^{2} \&$ HUA Lei ${ }^{1}$ \\ (1: Zhejiang Institute of Hydraulics \& Estuary, Hangzhou 310020, P. R. China) \\ (2: Hangzhou West Lake Administration, Hangzhou 310002, P. R. China)
}

\begin{abstract}
Through the integrated management including water diversion, the total phosphorus (TP) concentrations were decreased by $58 \%$ and $78 \%$, the total nitrogen ( TN) decreased by $16.7 \%$ and $7.7 \%$, and transparency raised by $100 \%$ to $200 \%$, respectively, in the outer West Lake and the inner West Lake. Eutrophication status was greatly reduced in the lake. Compared to the situation before the implementation of the program in 1986, due to the huge differences in inflow, diversion and drainage patterns, the characteristics of TP concentration variations within the year and their driving factors have great differences in different regions of the lake. In the upper lake region located in the west of Yanggongdi, TP concentration was low because of the supplement of high quality diverted water, and the concentrations increased in certain periods of time by the influences of rainfall-runoff non-point sources. The lake region between Yanggongdi and Sudi, TP concentration was the lowest and its variation was relatively stable, due to the large quantity of supplemented high-quality diverted water and the fastest water exchange. In outer lake area located in the east of Sudi, water exchange was slow, and TP concentrations reached the peak in summer because of the sediments release. Due to large quantity of water diversion and being lack of denitrification process, the variation of TN concentrations in the West Lake were the same as that in the intake river, Qiantang River, and the concentrations appeared to fluctuate in the same period of time for the rainfall-runoff non-point source. Based on the analysis of TP mass balance model, the spatial variation of water quality was primarily affected by the times of water exchange, and the pollutant load per volume of water secondary.
\end{abstract}

Keywords: West Lake; total phosphorus; total nitrogen; spatial and temporal distributions; impact factors

杭州西湖是驰名中外的游览胜地. 由于种种原因, 水质一度长年不佳, 水体呈富营养化, 降低了西湖的

* 国家水体污染控制与治理科技重大专项 (2012ZX07101-007-005) 资助. 2014-03-19 收稿;2014-10-28 收修改 稿. 尤爱菊(1974 ), 女,博士, 教授级高级工程师;E-mail:youaj@ zjwater. gov. cn. 
旅游价值和可持续开发的潜力. 为改善西湖水质, 数十年来杭州市投人了大量的人力、物力和财力开展西湖 的综合整治工作. 近代西湖综合整治包括湖底疏浚、人湖溪流整治、西湖西进、引配水、水域生态修复等措 施 $^{[1-2]}$. 其中西湖西进工程恢复了清朝乾隆以前、杨公堤以西曾存在的金沙港、茅家埠、乌龟潭、浴鹄湾 4 大 湖区, 新增湖面面积约 $0.7 \mathrm{~km}^{2}$, 湖区总面积从 $5.66 \mathrm{~km}^{2}$ 扩大至 $6.36 \mathrm{~km}^{2}$; 工程实施后, 西湖在流域形态上形 成了杨公堤以西的上游湖区、杨公堤至苏堤间的中游湖区和苏堤以东的下游湖区 (即外湖区). 引配水工程 始于 1986 年, 直引约 $2000 \times 10^{4} \mathrm{t} / \mathrm{a}$ 的钱塘江水人西湖; 2003 年对引水工程进行了扩建, 同时配套建设沉淀 除磷预处理工程, 引水规模增至 $40 \times 10^{4} \mathrm{t} / \mathrm{d}$. 引排水格局上 (图 1), 上游湖区从黄喪楼、乌龟潭、醉白楼 3 个 进水口共进水 $10 \times 10^{4} \mathrm{t} / \mathrm{d}$, 出水全部进人中游湖区; 中游湖区从小南湖进水口进水 $27 \times 10^{4} \mathrm{t} / \mathrm{d}$, 自岳湖葲站 抽排 $10 \times 10^{4} \mathrm{t} / \mathrm{d}$ 水进浙江大学护校河, 抽引 $2 \times 10^{4} \mathrm{t} / \mathrm{d}$ 水进北里湖,其余通过苏是 6 个桥孔排人下游湖区; 下游湖区从长桥溪进水口进水 $3 \times 10^{4} \mathrm{t} / \mathrm{d}$, 并与承泄的上游来水主要从圣塘闸外排.

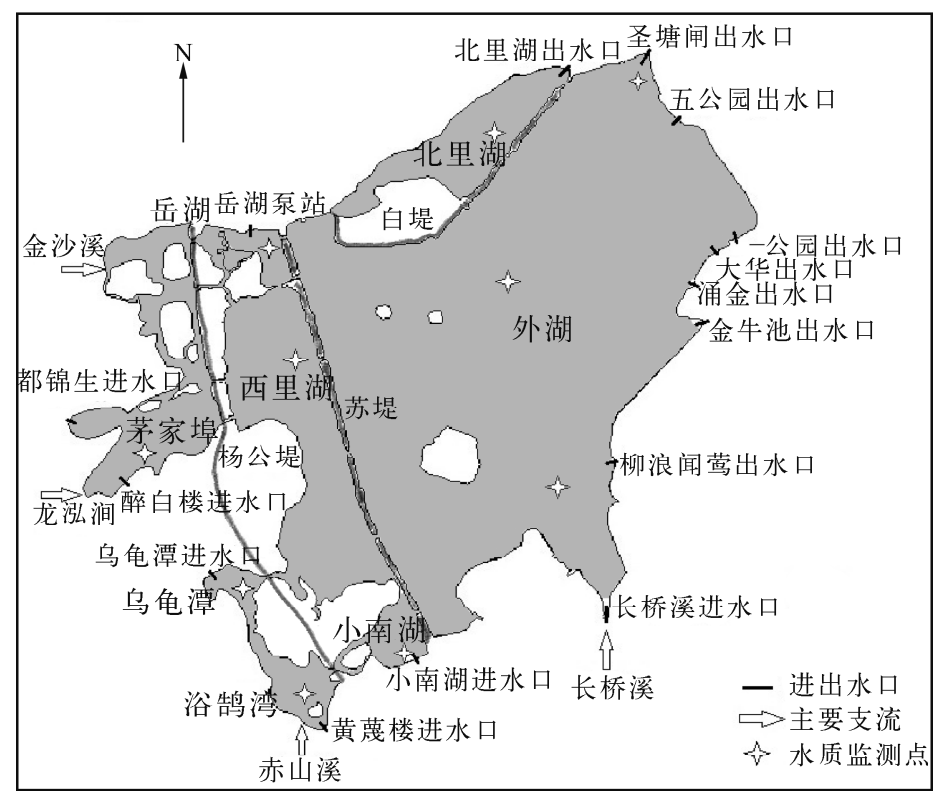

图 1 西湖湖区来水、布水和排水格局

Fig. 1 Inflow, water diversion and drainage in the West Lake

西湖实施综合整治及大规模引水配水后, 人湖污染负荷得到了有效控制, 水体更新能力增强, 水环境改 善趋势明显 ${ }^{[3-8]}$. 林丰妹等 ${ }^{[3]}$ 通过调查、监测, 发现西湖综合保护工程实施后, 流域内污染物削减明显, 入湖 溪流和西湖水质改善效果显著, 流域内生物多样性有所增加. 毛成责等 ${ }^{[4]}$ 于 2006 年 10 月-2007 年 9 月对西 湖 5 个主要湖区的理化因子和藻类生物量进行测定和分析, 探讨了西湖四季营养盐浓度变化与西湖水体富 营养化的关系. 张志兵等 ${ }^{[5]}$ 于 2006-2007 年对西湖浮游藻类的种类及个体丰度进行初步研究, 结果表明西 湖水质较整治前有明显改善,一些清水藻类的种类逐步增多. 杨俊等 ${ }^{[6]}$ 以西湖不同湖区 2012 年的逐月监测 资料为基础, 分析了西湖不同湖区氮、磷营养盐以及浮游植物的时空变化特征, 并对不同湖区富营养化现状 进行了评价. 近年来, 有关西湖水质、富营养化和生态因子的监测评价成果较多 ${ }^{[9-14]}$, 而针对西湖时间分段和 空间分区的水质变化特征、驱动因素及水质与影响因子的关联性定量研究成果较少. 总磷 (TP)、总氮 (TN) 是湖泊富营养化的主要控制因子 ${ }^{[15-16]}$, 本文主要采用 TP、TN 浓度实测资料, 分 4 个时期分析综合整治过程 中西湖水质的变化特点和治理成效; 通过与环境因子的关联性分析并结合 TP 质量平衡模型, 定量研究分区 $\mathrm{TP}$ 浓度差异及主要原因. 研究成果可为西湖今后的科学治理提供依据, 并为其它城市景观湖泊的治理提供 参考. 


\section{1 不同时期 TP、TN 治理成效}

西湖水质的常态化监测工作始于 1998 年, 此前仅有零星监测资料, 此后监测站点和指标不断调整, 至 目前共设有 15 个覆盖各湖区及主要人湖支流的监测点. 杨公堤以西的上游湖区及支流常规监测站主要建 设于综合整治后,故本次采用中游湖区和下游湖区的水质监测资料,分析西湖 TP、TN 4 个时期的变化特点 及治理成效. 分析的 4 个时期为: (1) 1985-1986 年,反映西湖综合治理前的本底情况; (2) 1987-2002 年,主 要反映西湖环湖污染源综合治理、流域治理、底泥疏浚和从钱塘江直引 $2000 \times 10^{4} \mathrm{t} / \mathrm{a}$ 水量的综合治理效果; (3) 2003-2010 年, 主要反映西湖引水规模扩大至 $40 \times 10^{4} \mathrm{t} / \mathrm{d}$, 湖区优化进出水口布局后的整治效果; (4) 2011-2013 年,主要反映西湖部分湖区实施生态修复工程的整治效果. 另根据 2008-2011 年各站点水 质监测结果, 同一湖区的不同监测点水质年内变化基本同步,且相同指标监测值较为接近,故本次研究分别 选用西里湖、外湖监测点为中游湖区、下游湖区的代表站点; 后文分析中以茅家埠监测点为上游湖区代表 站点.

\subsection{TP 治理成效}

西湖综合整治工程实施后, 由于人湖污染物得到有效控制,引大量优质水带来湖区水体年交换次数增 加,水体 TP 浓度峰值、均值都显著下降. 西里湖不同时期的 TP 平均浓度分别下降 $17 \%$ 、60\% 和 34\% , 全时 期累计下降 78\% ; 最大浓度在治理过程中略有上升,在后两个时期则分别下降 54\% 和 59\%, 全时期累计下 降 76\% . 外湖不同时期 TP 的平均浓度分别下降 20\%、35\% 和 19\% , 全时期累计下降 58\% ; 最大浓度下降 $12 \% 、 28 \%$ 和 $31 \%$, 全时期累计下降 $56 \%$. 两个湖区最小浓度变化不大, 故 TP 变幅大大降低, 湖泊水质更为 稳定 (表 1 ).

表 1 不同治理时期西里湖、外湖 TP 浓度变化*

Tab. 1 Variations of TP concentration in the inner West Lake and outer West Lake in different management periods

\begin{tabular}{|c|c|c|c|c|c|c|c|c|c|}
\hline \multirow[b]{2}{*}{ 监测点 } & \multirow{2}{*}{$\begin{array}{l}\text { 统计 } \\
\text { 参数 }\end{array}$} & \multicolumn{4}{|c|}{ 不同治理时期 TP 浓度/( mg/L) } & \multicolumn{4}{|c|}{ 阶段治理效果/\% } \\
\hline & & $\begin{array}{c}1 \\
1985-1986 \\
\end{array}$ & $\begin{array}{c}2 \\
\text { 年 } 1987-2002 \\
\end{array}$ & 年 $2003-2010$ & 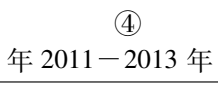 & $\begin{array}{l}\text { (1)-(2) } \\
\text { 时期 }\end{array}$ & $\begin{array}{l}\text { (2)-(3) } \\
\text { 时期 }\end{array}$ & $\begin{array}{l}\text { (3)-(4) } \\
\text { 时期 }\end{array}$ & $\begin{array}{l}\text { (1)-(4) } \\
\text { 时期 }\end{array}$ \\
\hline \multirow[t]{3}{*}{ 西里湖 } & 平均值 & 0.124 & 0.103 & 0.041 & 0.027 & 17 & 60 & 34 & 78 \\
\hline & 最大值 & 0.207 & 0.262 & 0.120 & 0.049 & -27 & 54 & 59 & 76 \\
\hline & 最小值 & 0.030 & 0.021 & 0.020 & 0.020 & - & - & - & - \\
\hline \multirow[t]{3}{*}{ 外湖 } & 平均值 & 0.110 & 0.088 & 0.057 & 0.046 & 20 & 35 & 19 & 58 \\
\hline & 最大值 & 0.189 & 0.166 & 0.120 & 0.083 & 12 & 28 & 31 & 56 \\
\hline & 最小值 & 0.014 & 0.020 & 0.018 & 0.018 & - & - & - & - \\
\hline
\end{tabular}

*阶段治理效果为该时期 TP 浓度变化量占该时期结束时 TP 浓度的百分比.

另外,不同时期因湖泊水质的主要影响因子不同,呈现不同的空间分布特征. 1985-1986 年综合治理前 及 1987-2002 年治理阶段,湖区水质主要受流域污染负荷影响,因西里湖直接承接流域负荷,故 TP 空间上 呈现西里湖较高、外湖略低的特征. 2003-2010 年治理阶段,钱塘江大规模引水 (经预处理) 实施后,引水布 局对湖区水质影响较大,因引水先进人西里湖湖区, 大量优质的补充水源极大提高了西里湖湖区的水体更 新能力, 使得西里湖 TP 浓度得到大幅下降; 而通过苏堤桥孔扩散至外湖后, 立即与外湖水体掺混, 浓度升 高, 浓度梯度迅速减小, 对水体的稀释、更新能力减弱,故外湖水质的改善程度相对较低. 2011-2013 年治理 阶段,在综合因素作用下, 西里湖沉水植物生态系统开始发挥作用,湖区水质进一步得到改善, 而外湖 TP 浓 度的下降主要是上游西里湖来水浓度降低所致,故改善幅度相对较小 (表 1 ).

\section{$1.2 \mathrm{TN}$ 治理成效}

相对于 TP, 不同时期 TN 的变化幅度较小, 外湖平均浓度总体下降 16.7\%, 西里湖下降 7.7\% . 西湖引水规 模扩大后, 并未作源水的脱氮预处理, 因此 TN 浓度的下降主要得益于西湖人湖污染源的综合整治. 根据相关 测算,一期综保工程实施后, 直接或渗排的人湖 TN 负荷减少 $16.99 \mathrm{t} / \mathrm{a}^{[3]}$. 流域来源的 TN 和引水携带的 TN 均 
先进人西里湖, 经其滞蓄后至下游湖区, 均值、最大值浓度均略有下降, 故外湖改善程度略高于西里湖 (图 2).
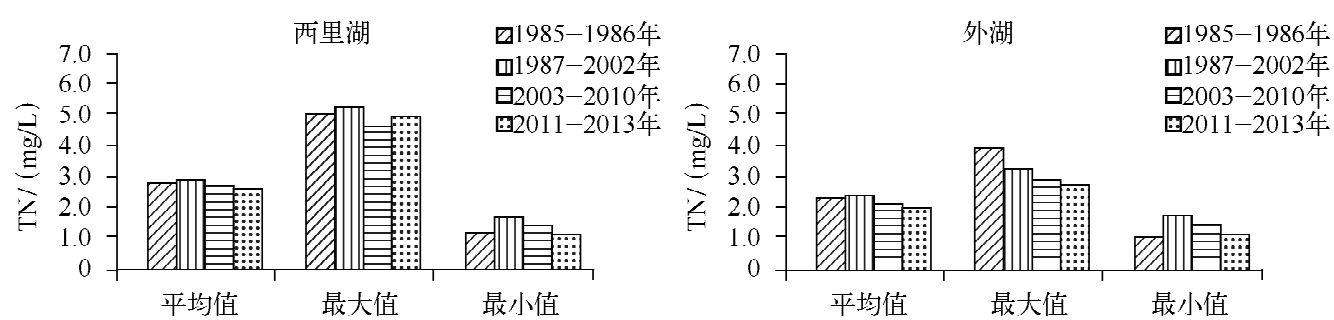

图 2 不同治理阶段西里湖及外湖 TN 浓度变化

Fig. 2 Variations of TN concentration in the inner West Lake and outer West Lake in different management periods

\section{3 其它指标}

西湖综合整治在大大降低 TP 浓度的同时, 湖区透明度得到显著提高, 外湖透明度从整治前的 $30 \sim$ $40 \mathrm{~cm}^{[1]}$ 提升到 $70 \sim 80 \mathrm{~cm}$, 而西里湖提高到 $100 \mathrm{~cm}$ 以上. 同时各湖区的叶绿素 a 浓度水平也显著下降, 外湖 年均浓度从治理前的 $160 \mu \mathrm{g} / \mathrm{L}$ 下降至 $50 \mu \mathrm{g} / \mathrm{L}$ 以下, 西里湖则下降至 $10 \mu \mathrm{g} / \mathrm{L}$ 以下. 根据综合营养状态指 数评价, 因 TP、叶绿素 a 浓度的下降及透明度的提高, 外湖从中度富营养化演变为轻度富营养化状态, 而西 里湖演变为中营养状态. 因此, 西湖治理通过对引水水源 TP 的控制, 使得湖区透明度和富营养化程度得到 极大改善, 说明 TP 是西湖富营养化的控制性指标.

\section{$2 \mathrm{TP} 、 \mathrm{TN}$ 年内变化及空间差异分析}

\subsection{TP 年内变化及空间差异}

西湖经流域综合整治后, 点源污染基本得到控制, 人湖 TP 负荷主要由流域面源负荷 ${ }^{[17]}$ 、湖泊底泥释放 的内源负荷、引水携带的负荷及湖面干湿沉降等组成. 其中引水经预处理后 TP 浓度全年较为稳定, 湖面干 湿沉降在总负荷中所占比重较小 ${ }^{[18]}$, 因此 TP 浓度的年内变化主要因降雨驱动的流域面源污染和气温驱动 的内源污染变化引起. 但由于补充水源水量、水质的差异, 各湖区受降雨、气温变化的影响程度也不同. 采用 2011 年实测资料对西湖水质的空间差异及与驱动因子的关联性进行分析,结果见图 3、图 4.

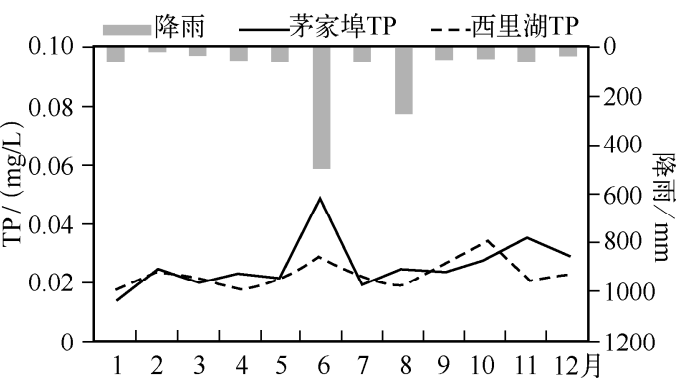

图 3 上游、中游湖区 TP 浓度、降水年内同步过程

Fig. 3 Synchronous process of rainfall and TP concentration in upstream and midstream of the lake within the year

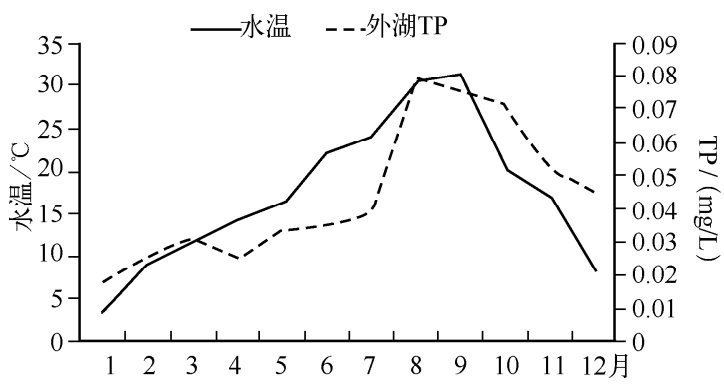

图 4 下游湖区 TP 浓度、水温年内同步过程

Fig. 4 Synchronous process of water temperature and TP concentration in downstream of the lake within the year

从图 3 可见,西湖上游、中游湖区 TP 浓度全年较低,在降雨集中的 6 月份出现峰值, 尤其是茅家埠站代 表的上游湖区更为明显;8 月茅家埠站因降雨 TP 浓度再次抬升, 但由于降雨量相对较小, 西里湖站因有稳定 的优质引水输人, 故 TP 浓度受降雨影响不明显. 10、11 月两站 TP 浓度先后再次出现峰值, 对比图 4 中的水 温变化过程结合相关实验研究结果 ${ }^{[19-20]}$, 主要是由水温升高致使底泥释放增加引起; 其中上游湖区抬升幅 
度不及降雨引起的 6 月峰值, 而中游湖区抬升幅度超过因降雨引起的 6 月峰值.

下游湖区 TP 浓度年内变化过程与上游、中游湖区存在显著差异, 下游湖区 TP 浓度在降雨集中的 6 月 份并无明显的升高现象,而在水温较高的 8-10月份, TP 浓度持续升高并出现峰值(图 4). 由此可见,流域 径流面源污染经上游湖区、中游湖区调蓄净化后, 对下游湖区的影响明显减弱, 而高温期底泥内源释放的 TP 负荷是造成下游湖区出现高浓度的主要原因; 此外从图 4 可见,水体 TP 浓度的升高和回落与水温过程相比 有一个明显的滞后期,过程是合理的.

综合图 3 、图 4,外湖全年 TP 浓度变化受水温影响最为明显; 茅家埠全年 TP 浓度变化受降雨影响最为 明显; 而西里湖因有上游对流域面源污染的初步拦截, 同时承纳大量水质稳定的外来引水 (经除磷预处理), 全年 TP 浓度最低且最为稳定. 根据年内各月实测 TP 浓度, 外湖、西里湖、茅家埠 TP 浓度年内均方差分别为 $0.020 、 0.009$ 和 $0.006 \mathrm{mg} / \mathrm{L}$, 以外湖变幅最大,西里湖变幅最小. 各湖区 TP 浓度除时间分布不均匀外,空间 分布也不均匀:2011 年 1-3 月低温期外湖 TP 浓度为西里湖的 1.2 倍, 而 8-10 月高温期则达到 2.8 倍; 这 也说明外湖将是当前及未来一段时期内,西湖治理的重点区域.

\section{$2.2 \mathrm{TN}$ 年内变化及空间差异}

因钱塘江引水未作降氮处理, 故湖区 TN 浓度既受外来引水的影响, 也受流域面源负荷 ${ }^{[17]}$ 、湖泊内源负 荷和湖区干湿沉降的影响. 因从钱塘江引水量 较大,西湖各湖区 $\mathrm{TN}$ 年内浓度变化总体上和钱 塘江引水口 $\mathrm{TN}$ 浓度变化较为同步,但在降水量 较大的 6 月,各湖区 TN 浓度均出现峰值. 此外, 从各湖区的 TN 浓度大小看, 上游湖区因直接接 纳流域负荷, 因此 TN 浓度相对最高, 且受降雨 的影响也更显著; 中游湖区、下游湖区经上游湖 区对流域负荷及引水负荷的滞蓄和消纳后, TN 浓度均有明显下降, 且受降雨影响的程度也明 显减小. 对比水温变化过程,各湖区 TN 浓度均 无随水温升高而升高的现象, 反而在水温较高 的 8-10 月份出现降低现象, 有学者认为和水体 中微生物的活跃性有关 ${ }^{[6]}$, 但有待进一步证实

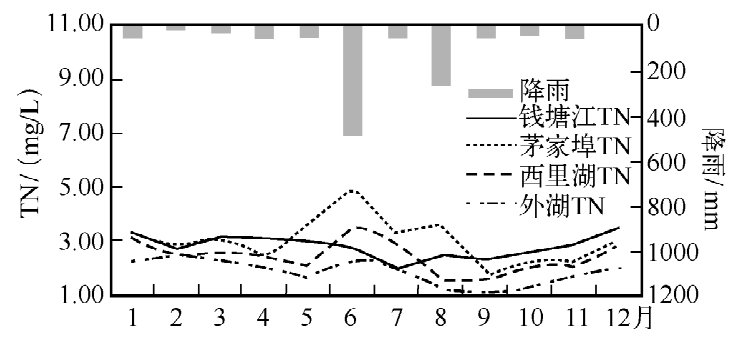

图 5 西湖各湖区 $\mathrm{TN}$ 及同期钱塘江 取水口 TN、降雨过程

Fig. 5 TN concentration in the West Lake and the inlet of Qiantang River, and rainfall at the same period (图 5).

\section{TP 分区差异定量分析}

西湖 TP 浓度及其变化的分区差异,从驱动因素来看主要是降雨、引水和水温造成底泥释放 TP 负荷的 影响程度不同所致,但从机理来看主要是承纳的污染负荷和水体交换时间不同所致. 采用文献 [22-23]建立 的西湖 TP 模型, 对不同湖区的水质差异进行定量分析.

$\mathrm{TP}$ 浓度质量平衡模型 (budget models) 是全混合模型. 对于年 (或月) 的稳定状态, 全混合模型可假定流 出磷的浓度与湖区充分混合稳定浓度相同,且流人、流出水体相同. 稳定状态下 TP 浓度计算式为:

$$
p=\frac{\sum_{i=1}^{n} W_{i}}{\sum_{i=1}^{n} Q_{i}+k_{\mathrm{S}} \cdot V}
$$

式中, $p$ 为分区水体的 $\mathrm{TP}$ 浓度 $\left(\mathrm{g} / \mathrm{m}^{3}\right.$ 或 $\left.\mathrm{mg} / \mathrm{L}\right) ; \sum_{i=1}^{n} W_{i}$ 为进人湖区的各类 TP 年负荷 $(\mathrm{mg} / \mathrm{a})$, 其中 $i=1 \sim n$ 为流域产磷、底泥释磷、引水携带等各类人湖污染负荷; $\sum_{i=1}^{n} Q_{i}$ 为进人 (流出) 西湖的年总水量 $\left(\mathrm{m}^{3}\right), i=1 \sim n$ 指流域径流、引水等各类人湖水量; $k_{\mathrm{S}}$ 为沉降到西湖底泥磷负荷的一阶沉降率 $\left(\mathrm{a}^{-1}\right) ; V$ 为分区水体的容积 $\left(\mathrm{m}^{3}\right)$.

将公式(1) 分子、分母均除以水体容积 $V$, 则可得分子项为 $\sum_{i=1}^{n} W_{i} / V$, 表征单位体积承纳的 $\mathrm{TP}$ 污染负 
荷 $\left(\mathrm{g} / \mathrm{m}^{3}\right)$, 值越小表明 TP 浓度越小. 分母第一项为 $\sum_{i=1}^{n} Q_{i} / V$, 表征水体年交换次数 $t_{i}$, 交换次数越多表明 $\mathrm{TP}$ 浓度越小. 参照前文分析, 污染负荷上游湖区主要来自径流面源污染和引水携带人湖的污染负荷, 中游湖 区主要来自人湖水体携带的污染负荷, 下游湖区主要来自人湖水体携带的污染负荷及底泥释放污染负荷. 采用 2011 年流域降雨、支流及湖区水质观测资料, 参照西湖底泥释放和面源实验观测的有关研究成 果 ${ }^{[17-23]}$, 可测算各湖区年人湖负荷量; 各湖区人湖水量主要是流域径流和引水水量; 基于 2011 年人湖水量 和污染负荷测算结果,计算得到各湖区单位体积承纳的污染负荷 $W_{i}$ 和水体交换时间 $t_{i}$ (表 2). 按文献 [22] 推荐的 $k_{\mathrm{S}}$ 取值 $10 / H$ ( $H$ 为平均水深), 则可采用公式(1) 反演各湖区的 TP 浓度(表 2).

湖区 TP 浓度的差异取决于单位水体负荷量和水体年交换次数的差异. 从表 2 可见, 各湖区水体年交换 次数的差异大于单位水体负荷量的差异, 因此, 水体年交换次数差异是主要影响因子. 中游湖区因承受大量 外来引水, 尽管单位体积负荷量最大, 但其水体年交换次数亦最大, 单位水量负荷量 $\left(\sum_{i=1}^{n} W_{i} / Q\right)$ 最低, 故 年均 TP 浓度亦最低; 外湖区因水体容积最大, 单位体积负荷量最小, 但因水体年交换次数最小, 单位水量负 荷量最大, 故年均 TP 浓度最高. 此外, 经综合整治后, 各湖区年平均 TP 浓度均已达到地表水 III 类标准, 但外 湖区在 8-10 月高峰期 TP 浓度可达 $0.05 \sim 0.10 \mathrm{mg} / \mathrm{L}$, 叶绿素 a 浓度接近 $100 \mu \mathrm{g} / \mathrm{L}$, 仍存在时段性的藻类 暴发的威胁, 故外湖区将是未来一段时期内西湖治理的重点区域. 根据公式 (1), 为降低下游湖区 TP 浓度, 理论上一方面可通过削减人湖负荷进一步降低单位体积的污染负荷, 另一方面可通过扩大引水规模以增加 年换水次数. 具体治理措施还需要从技术、经济和政策处理等可行性方面作进一步详细论证.

表 2 西湖各湖区特征参数

Fig. 2 Characteristic parameters in different regions of the West Lake

\begin{tabular}{|c|c|c|c|c|c|c|c|c|}
\hline 湖区 & $\begin{array}{c}\text { 面积/ } \\
\mathrm{km}^{2}\end{array}$ & $\begin{array}{c}\text { 容积/ } \\
\left(\times 10^{4} \mathrm{~m}^{3}\right)\end{array}$ & $\begin{array}{c}\text { 年人湖水量/ } \\
\left(\times 10^{4} \mathrm{~m}^{3}\right)\end{array}$ & $\begin{array}{c}\text { 年污染负荷量/ } \\
\text { (t/a) }\end{array}$ & $\begin{array}{c}\text { 单位体积负荷量/ } \\
\left(\mathrm{g} / \mathrm{m}^{3}\right)\end{array}$ & $\begin{array}{l}\text { 年交换 } \\
\text { 次数 }\end{array}$ & $\begin{array}{l}\text { 实测年均 TP } \\
\text { 浓度/ ( mg/L) }\end{array}$ & $\begin{array}{l}\text { 计算年均 TP } \\
\text { 浓度/ }(\mathrm{mg} / \mathrm{L})\end{array}$ \\
\hline 上游湖区 & 0.70 & 163 & 4620 & 1.38 & 0.85 & 28 & 0.026 & 0.027 \\
\hline 中游湖区 & 0.93 & 220 & 13720 & 3.37 & 1.53 & 62 & 0.023 & 0.024 \\
\hline 下游湖区 & 4.34 & 983 & 13000 & 7.31 & 0.74 & 12 & 0.044 & 0.046 \\
\hline
\end{tabular}

\section{4 结语}

1）西湖综合保护工程实施以来,外湖、西里湖 TP 浓度累计下降 58\% 和 78\%, TN 浓度累计下降 16.7\% 和 $7.7 \%$, 透明度提高了 $100 \% \sim 200 \%$, 富营养状态得到极大缓解, 治理成效显著. 相关研究提出西湖是一个 典型的磷限制型富营养化湖泊 ${ }^{[4]}$, 本文从控磷带来西湖水质和富营养化改善的情况, 也证实了这一点. 因 此, 今后西湖富营养化的治理, 需要以进一步控制外源和内源输人的 TP 负荷为主.

2) 目前西湖进、排水口过于集中, 因此水质空间差异极大. 大量优质引水仅小南湖一个主进水口和圣塘 闸一个主出水口, 各湖区 TP、TN 在时间和空间上变化均存在差异, 且主要的影响因子及其对各湖区的影响 程度也不同. 苏堤上游湖区经流域综合治理和大规模集中引水后, 全年 TP 维持在 $0.05 \mathrm{mg} / \mathrm{L}$ 以下, 但在 $8-$ 10 月高温期, 外湖区因内源污染释放累积 TP 浓度可达 $0.08 \sim 0.10 \mathrm{mg} / \mathrm{L}$, 仍存在营养盐的 “高浓度区”, 依 旧面临“水华”暴发的风险. 因此,外湖区将是未来一段时期西湖治理的重点水域.

3) TP 模型定量分析表明, 水体年交换次数低、高温期因底泥释放单位水量污染负荷大是外湖区 TP 浓 度较高的主要原因. 应进一步开展全湖引排水格局优化、湖区底泥污染治理、流域污染源控制与管理及扩大 引水规模等方面的研究工作, 以进一步提高全湖 TP 浓度均匀度、减少外湖 TP 高浓度值出现的历时和范围.

\section{5 参考文献}

[1] 郑 瑾. 西湖治理史研究. 杭州: 浙江大学出版社, 2010 .

[2] 张建庭.碧波盈盈: 杭州西湖水域的综合保护与整治. 杭州: 杭州出版社,2003.

[ 3 ] 林丰妹, 叶旭红, 焦 荔等. 综合保护工程对杭州西湖生态环境的影响. 水资源与水工程学报, 2007, 18 (6) :52-55.

[ 4 ] 毛成责, 余雪芳, 邵晓阳. 杭州西湖总氮、总磷周年变化与水体富营养化研究. 水生态学杂志, 2010,3(4):1-7. 
[ 5 ] 张志兵,施心路,刘桂杰等. 杭州西湖浮游藻类变化规律与水质的关系. 生态学报,2009,29(6):2980-2988.

[6] 杨 俊, 吴芝瑛, 徐 骏等. 西湖不同湖区营养盐特征及富营养化现状研究. 环境科学导报, 2014,33(3):8-12.

[ 7 ] Yu ZM, Yan LJ, Wu J. Studies on the changes of West lake's zoobenthic communities after Qiantang River water was pumped into it. Journal of Zhejiang University, 2002, 3(1):118-124.

[ 8 ] Wei YX, Li J, Yu ZM. Phytoplankton community dynamics in west lake after drawing water from the Qiantang River. Chinese Journal of Oceanology and Limnology, 2004,22(2) :176-185.

［9］朱军政,韩曾萃. 西湖总磷浓度对引水配置布局的响应. 水文,2013,(5):34-38.

[10］李琳琳,汤祥明,高 光等. 沉水植物生态修复对西湖细菌多样性及群落结构的影响. 湖泊科学, 2013, 15 (2): 188-198.

[11] 饶利华, 吴芝瑛, 徐 骏等. 杭州西湖轮虫的群落结构及与水体环境因子的关系. 湖泊科学, 2013,24(6): 138-146.

[12] Cai LL, Zhou QH, He F et al. Investigation of microbial community structure with culture-dependent and independent PCR-DGGE methods in western west lake of Hangzhou, China. Fresenius Environmental Bulletin, 2012, 21 ( 6 ): 1357-1364.

[13] Yuan F, Guo LX, Miao ML et al. Diversity analysis of Burkholderia cepacia complex in the water bodies of west lake, Hangzhou, China. The Journal of Microbiology, 2011,49 (2):309-314.

[14] Wang ZD, Li S, Zhu J et al. Phosphorus partitioning between sediment and water in the riparian wetland in response to the hydrological regimes. Chemosphere, $2013, \mathbf{9 0}(8)$ ):2288-2296.

[15] 金相灿. 湖泊富营养化控制和管理技术. 北京:化学工业出版社,2001.

[16] 秦伯强. 富营养化湖泊治理的理论与实践. 北京:高等教育出版社,2011.

[17] 唐孟成,俞秋红, 王寿祥. 雨后人湖溪流磷污染对西湖的影响及其对策. 环境污染与防治, 2003,25(1):12-15.

[18] 焦 锋,秦惠平, 秦伯强等. 北里湖总氮、总磷主要输人外源辨识. 河海大学学报: 自然科学版, 2012, 40 (2): 148-155.

[19］韩伟明. 底泥释磷及其对杭州西湖富营养化的影响. 湖泊科学, 1993,5(1):71-77.

[20] 吴根福,吴雪昌,金承涛等. 杭州西湖底泥释磷的初步研究. 环境科学研究, 1998,18(2): 107-110.

[21］王京文,孙吉林,张奇春等. 西湖名胜区溪流富营养化现状评价. 浙江农业科学,2013,(2):202-204.

[22］韩曾萃,朱军政,江 影等. 杭州西湖 TP 模型及其治理应用( I ). 环境污染与防治,2005,27(2):139-141.

[23] 韩曾萃,朱军政,江 影等. 杭州西湖 TP 模型及其治理应用 ( II ). 环境污染与防治,2005,27(3):181-183. 